\title{
Humor, ciência e politica em Isabelle Stengers
}

\author{
Humor, science, and politics \\ in Isabelle Stengers \\ Márcia de Oliveira Teixeira \\ Assistente de pesquisa da \\ Escola Politécnica de Saúde Joaquim Venâncio, Fiocruz \\ Av. Brasil, 4365 \\ 21045-000 Rio de Janeiro - RJ Brasil \\ marciat@fiocruz.br/marciat23@hotmail.com
}

Isabelle Stengers A invenção das ciências modernas, tradução de Max Altman Rio de Janeiro, Editora 34, 2002, 208p.
Eu gostaria de tornar possível o riso de humor que compreende, aprecia sem esperar a salvação e pode recusar sem se deixar aterrorizar (Stengers, p. 29).
$\mathrm{D}$ ona de um texto envolvente, por vezes barroco, recheado com o diálogo com filósofos, historiadores e sociólogos, representados vez ou outra por tipos como o 'epistemólogo-juiz' ou o ‘sociólogo irônico', Isabelle Stengers convida-nos à discussão sobre a "nvenção das ciências modernas". Projeto sem dúvida ambicioso, cujo traço peculiar é a erudição desta química, doutora em filosofia da ciência, professora de filosofia da Universidade Livre de Bruxelas, além de autora de diversos livros, alguns já publicados por editoras nacionais. Como se a 'invenção' se debruçasse sob o campo minado, estendido entre as teses da objetividade das ciências hard e de sua construção social. Todavia, a autora cumpre sua tarefa tomando os dois aspectos como invenções.

A densidade da problemática circunscrita por Stengers neste trabalho é enfrentada com um permanente apelo ao humor, carregado por uma significativa intencionalidade: não se deixar capturar pelo poder que embala as ciências desde que elas abandonaram as rodas noturnas e os coquetes do século XVIII. Trata-se de um humor rebuscado, reminiscência dos salões do Ancien Régime, nos quais as ciências eram um palpitante tema de saraus. A capacidade de rir não guarda relação com a troça, tampouco com o descompromisso, mas com a possibilidade de discutir as ciências e sobretudo as práticas científicas, inclusive por parte daqueles que tomaram a ciência como objeto - sociólogos, historiadores e filósofos. Ao longo de nove capítulos, divididos em três partes, Isabelle Stengers exercita-se contra a sacralização das ciências, explora a produção de sociólogos, historiadores e filósofos, defende a singularidade das ciências e, por fim, propõe formas de discutir tanto as ciências quanto suas invenções.

O título traz inquietação. Embora 'invenção' nos remeta ao engedramento e à maquinação ardilosa, histórica e sociologicamente o termo pertence a uma matriz de pensamento distinta de 'construção' ou 'produção', comumente utilizadas a partir da década de 1960. A suposta falta de rigor aplaca-se quando consideramos o apelo à invenção como distinção política, uma lembrança de que os conhecimentos históricos e sociais não deixam 
de reivindicar um tipo de objetividade e também são socialmente construídos. Os sociólogos afirmam-se como produtores de fatos sobre as ciências. Há invenções analisando uma invenção, ou seja, diferentes postulados sociológicos (também históricos e filosóficos) discutindo e interpretando a invenção de um conjunto de práticas experimentais e de um universo (ao seu modo) fechado - o laboratório. 'Invenção' envolve tanto a astúcia das ciências hard e das histórico-sociais para engendrar formas de fazer a diferença entre fato e ficção, quanto as explicações sociais de como as ciências fazem esta diferença.

O desafio desse livro é, portanto, conseguir articular aquilo que entendemos por ciência com o que entendemos por política, sem ferir todos os 'sentimentos', mas aqueles que chamarei, a exemplo de Leibniz, os sentimentos estabelecidos, os que marcam, os que não se pode ameaçar sem acarretar a rigidez do pânico, a indignação, o malentendido (p. 26).

Cabe referência cuidadosa aos limites do exercício da invenção e ao risco da redução. Os 'sentimentos estabelecidos' denunciam a margem perigosa para além da qual cessa o diálogo, perde-se o humor criativo e crítico e fica-se refém do poder. Diante do argumento autoritário não há discussão das práticas científicas e, segundo Stengers, perde-se a dimensão da singularidade. Não há motivos para discorrer sobre as práticas, pois o poder decerto explica tudo.

Em oposição, a autora propõe a discussão das práticas científicas sem se eximir de considerar sua autoridade em contextos sociais específicos. Todavia afasta qualquer redução de sua obra a uma análise do poder da ciência, ansiando antes por uma discussão política desta. Isso implica situar os inventores, perseguindo o modo como eles participam de uma experiência social singular - viver em um mundo cujo conhecimento é produzido em um lugar único, o laboratório. Os praticantes da ciência e os cientistas que os analisam, bem como as suas práticas encontram-se em uma arena política ocupando posições distintas, a despeito de utilizarem as mesmas ferramentas e produzirem discursos baseados na autoridade da ciência. Esse partilhamento do campo político impõe respeito aos sentimentos e, simultaneamente, dessacralização da ciência. Sociólogos, historiadores e filósofos não estão 'fora' de um mundo (ele próprio) singularizado pelas ciências, fazendo de muitos modos uma crônica dos tempos presentes. A denúncia de tudo feito 'em nome da ciência' também não deveria ser invocada para explicar as ciências, sob pena de se ficar refém do seu poder.

Dentre os sentimentos feridos, o livro destaca a desconstrução da singularidade das ciências. A perda da singularidade explicaria, segundo Stengers, por que o tipo de análise sociológica da produção dos conhecimentos e artefatos tecnocientíficos, iniciada pelas Escolas de Barth e Edinburg na década de 1970 (Pickering, 1992), tanto desconforto trouxe aos pesquisadores das ciências ditas hard. A negação da singularidade assegurou-lhes o questionamento do poder inconteste das ciências, bem como a possibilidade de tomá-las como uma forma de prática social. Esse deslocamento está na base da transformação das ciências em objeto de investigação sociológica (Bloor, 1976).

Porém, para Stengers, a ciência como atividade humana reafirma-se na sua singularidade, cristalizada na prática experimental, bem como na atualização 
da transformação de fatos em ficções. Assim, a autora procura contrapor-se à produção iniciada pelas Escolas de Barth e Edinburg, esta última sistematizada no Programa Forte (idem, ibidem). E o faz de um modo engenhoso, utilizando-se das ciências políticas e de suas possíveis singularidades em relação às ações políticas disseminadas pela sociedade. De certo modo, ela nos leva a questionar se a perda da singularidade das ciências políticas, em lugar de desconstruir a cientificidade, não resultaria na diluição das diferenças entre o seu modo de entender as ações políticas e as interpretações da sociedade. Caso não houvesse diferenças entre as suas práticas, ainda haveria ciências políticas e um objeto para sociologia da ciência?

A perda da singularidade das ciências tem implicações na demarcação dos limites entre ciência e não-ciência, demarcação aliás central para o tipo de análise apregoada por Stengers: a análise política das ciências. Central para o projeto de respeitar os sentimentos estabelecidos, ou seja, os limites do espaço político capaz de reunir os pesquisadores aos intérpretes/ inventores de sua prática. De certo modo, ao questionarem a singularidade, alguns intérpretes rompem os limites.

O que está em jogo nessa questão toda da autonomia das ciências é a distinção entre aqueles que têm o direito de intervir nos debates científicos, de propor critérios, prioridades, questões, e aqueles que não o têm. A oposição dos cientistas a toda a sociologia das ciências pode então ser entendida em termos políticos: "... a singularidade das comunidades científicas manifestase, por sua vez, no fato de que elas exigem de seu meio que este reconheça a distinção entre os resultados de sua atividade e a totalidade das outras produções humanas" (p. 82).

Stengers concentra-se no antagonismo ciência/não-ciência, indagando: "é isso científico?" (p. 92). A mesma pergunta sustenta, de igual modo, sua argumentação a favor da singularidade. Para ela, a resposta em diferentes épocas constituiu a base de uma singularidade — as ciências modernas. Para tanto, discorre sobre o caso Galileu.

A argumentação focaliza-se em duas proposições: tomar as ciências modernas como processo contingente, inspirada em Deleuze e Guattari (1991); e no poder da ficção. A contingência nega simultaneamente explicações baseadas no encadeamento inexorável entre fatos, problemas e soluções e no arbitrário que tudo atribui ao contexto. Antes, Stengers salienta um processo no qual outros problemas, outras perguntas e outras respostas vão sendo colocados produzindo um campo de invenção. Galileu e seu plano inclinado podem ser tomados como campo de invenção: “... Galileu nos apresenta ao mesmo tempo o problema de um acontecimento e uma primeira exploração de seus seguimentos, da significação que Galileu, tal como ele é criado-situado-produzido pelo acontecimento" (pp. 90-1). Enquanto que o poder da ficção é a evidência sobre a qual ou contra qual as ciências modernas se mobilizam; o poder da ficção vivifica a indagação "isso é científico?", renovando o campo da invenção sob o qual as ciências modernas buscam se estabilizar. Na contraposição ao poder da ficção estão os ensaios experimentais e sua sistematização. Porém as ciências modernas não suplantam o poder da ficção, mas inventam seu campo a partir dele. Stengers apresenta uma primeira formulação para a singularidade das ciências modernas — inventar meios de fazer a diferença entre as ficções. 
A ficção inverte ou anula a contingência do processo científico, por 'ter', supostamente, um poder. Nela anulam-se as relações estabelecidas entre heterogeneidades, as mediações que distinguem as etapas do experimento e a longa fila de interessados (p. 115). Todavia esta ligação coloca as ciências modernas como 'equivalentes' às ciências teórico-experimentais. No capítulo 'O sujeito e o objeto', essa 'equivalência', é discutida, bem como a vinculação entre ciência e poder (das testemunhas contra a ficção).

Tratar-se-ia então de tentar 'estender' a singularidade das práticas científicas - inventada a propósito das ciências experimentais - a outros campos, ou seja, de desvincular também essa singularidade da invenção de um poder, da invenção de meios para criar testemunhas fidedignas (p. 159).

Stengers procura verificar quanto sua formulação para a singularidade resiste, discutindo a relação sujeito-objeto, cuja distinção foi alvo de uma série de debates na década de 1990 (Woolgar, 1996). Defende a distinção, todavia desconsiderando a imobilidade entre sujeito e objeto. Quando consideramos as ciências modernas como invenção renovada de meios para fazer a diferença com a ficção, sujeito e objeto figuram como atribuições fixas e irrevogáveis. Todo e qualquer deslocamento de sentido só se dá entre fato e ficção. Quando cai a ênfase no 'fazer a diferença com a ficção', essas atribuições deslocam-se, enquanto nossa capacidade prévia de dizer 'sujeito' e 'objeto' se esvai. Há deslocamentos e criação de novos sentidos (de sujeito e objeto) no interior das práticas experimentais, segundo os quais Stengers reformula sua definição da singularidade.

... trata-se ainda de inventar as práticas que tornarão nossas opiniões vulneráveis em relação a algo irredutível a uma outra opinião. ... nem o homem nem a coisa tem o domínio da medida, em que é a invenção de novas medidas ou seja, de novas relações e de novos testes, que distribui as respectivas identidades do homem e da coisa (p. 162).

Essa singularidade, a um só tempo abstrata, totalmente mergulhada no campo de relações políticas, e desvinculada de 'um' poder previamente estabelecido, é discutida à luz das transformações advindas com a introdução das simulações via computador em campos como o da matemática. Um ponto peculiar, quando confrontamos a leitura desse capítulo com a narrativa do caso Galileu, é a imaterialidade das provas a princípio utilizadas contra a ficção. Nada mais como a concretude do dispositivo de Galileu (o plano inclinado). Mesmo para pensamos a ficção, precisamos agora de registros diversos. Para Stengers, ocorreram deslocamentos políticos envolvendo provas, ficção, problemas, sujeitos e objetos, mas eles não afetaram a singularidade tal qual sua última enunciação. A ciência moderna permanece 'fazendo existir' algo e buscando modos de 'provar sua existência', mas esse algo, suas formas e as provas são totalmente contingentes e deparam, assídua e insistentemente, com a necessidade de formatar a prova segundo a responsabilidade ética, com a criação de novos sentidos.

'Devir' é o nome do último capítulo, em que os diálogos com Bruno Latour, Gilles Deleuze e Karl Popper acontecem conjuntamente. 'Devir' marca o potencial de desdobramentos da 'invenção' ou da capacidade de 
os inventores atualizarem sua invenção em processos de longa duração. Nele discutem-se as metamorfoses das ciências, sobretudo com as transformações advindas a partir das simulações e dos conflitos éticos.

Ao aproximar-me do final, penso ser necessário fazer algumas poucas considerações sobre o diálogo entre Isabelle Stengers e a dita 'sociologia da ciência'. Há um primeiro problema de demarcação de campo. Poucos sociólogos, dentre os que guardam alguma relação com as produções das escolas de Edinburg e de Barth, sentem-se confortáveis descrevendo seu campo como 'sociologia da ciência' (Latour, 2000). Mas as possíveis dificul-dades de diálogo — capazes de aturdir o leitor — estão nas diferenças que animam a produção de Isabelle Stengers e desses sociólogos. Stengers procura modos de lidar com a singularidade, perseguindo os contornos adquiridos nos longos processos de metamorfose. É na comparabilidade e no confronto de realidades que a singularidade das ciências modernas é delineada, sem brechas para as reduções. A singularidade defendida por Stengers não decorre da análise da origem (caso Galileu), mas situa-se no interior dos processos políticos envolvidos na constituição das ciências. Assim, a narrativa de Stengers centra-se em processos de longa duração, permitindo o entrelace de autores diversos como Bruno Latour, Karl Popper e Sandra Harding. Ela elabora um intricado patchwork, sem concessões para a homogeneidade.

Os sociólogos, por seu turno, buscam lidar com a diversidade aferrandose à impossibilidade de qualquer forma de singularidade de longa duração. A singularidade adquire sentidos diversos na obra de Stengers e na dos sociólogos pós-Programa Forte.

A tradição aberta com o Programa Forte atribui importância ao estudo do cotidiano dos laboratórios, às descrições etnográficas das práticas experimentais e à dissecação rigorosa da formatação de artigos científicos. Estas ênfases deram o tom de parte significativa da discussão sociológica das ciências na década de 1980. De certo modo atribuíram algumas 'singularidades' às 'práticas' científicas, alteradas, contudo, a cada conjuntura. O ponto é a impossibilidade de redução das singularidades das práticas tecnocientíficas à singularidade da ciência como prática social. Os sociólogos, a partir do Programa Forte e da leitura crítica da obra de Kuhn, estabelecem uma equivalência entre a discussão das ciências e de suas práticas científicas. Realizam, para Stengers, uma redução, enquanto que ela convida-nos ao debate da ciência, considerando-a irredutível às suas práticas. Há uma diferença radical no estatuto da singularidade, produzida pelo esvaziamento da dimensão ontológica 'da ciência', deslocada para o modo como 'suas práticas' produzem ontologias. 


\section{REFERÊNCIAS BIBLIOGRÁFICAS}

Bloor, D.

1976

Deleuze, Gilles e

Guattari, F.

1991

Latour, Bruno

2000

Pickering, Andrew 1992

Woolgar, Steve

1996
Sociologie de la logique ou les limites de l'epistémologie. Paris, Pandore.

Qu'est-ce que la philosophie. Paris, Editions Minuit (trad. bras., O que é a filosofia. Rio de Janeiro, Editora 34, 1992).

Ciência em ação.

Rio de Janeiro, Editora 34.

'From Science as knowledge to science as practice'. Em __. (org.). Science as practice and culture. Londres, The University of Chicago Press.

'O fim da cognição?

Os estudos da ciência e tecnologia desafiam o conceito de agente cognitivo'. História, Ciência, Saúde-Manguinhos, vol. II(3), pp. 105-33. 